
\title{
$\begin{array}{ll}\text { Research Square } & \begin{array}{l}\text { Preprints are preliminary reports that have not undergone peer review. } \\ \text { They should not be considered conclusive, used to inform clinical practice, } \\ \text { or referenced by the media as validated information. }\end{array}\end{array}$
}

\section{A Refined Procedure for Esophageal Resection Using a Full Minimally Invasive Approach}

\author{
Simon Ashiku ( $\nabla$ simon.k.ashiku@kp.org ) \\ Kaiser Permanente Northern California \\ Ashish R. Patel \\ Kaiser Permanente Oakland Medical Center \\ Brandon H. Horton \\ Kaiser Permanente Division of Research \\ Jeffrey Velotta \\ Kaiser Permanente Oakland Medical Center \\ Sora Ely \\ Kaiser Permanente Oakland Medical Center \\ Andrew L. Avins \\ Kaiser Permanente Division of Research
}

\section{Research article}

Keywords: Esophagectomy, Esophageal cancer, Minimally invasive surgery

Posted Date: May 18th, 2021

DOI: https://doi.org/10.21203/rs.3.rs-528094/v1

License: (c) (i) This work is licensed under a Creative Commons Attribution 4.0 International License. Read Full License

Version of Record: A version of this preprint was published at Journal of Cardiothoracic Surgery on March 4th, 2022. See the published version at https://doi.org/10.1186/s13019-022-01765-2. 


\section{Abstract}

Objective: Newer minimally invasive approaches to esophagectomy have brought substantial benefits to esophageal-cancer patients and continue to improve. We report here our experience with a streamlined procedure as part of a comprehensive perioperative-care program that provides additional advances in the continued evolution of this procedure.

Methods: All patients with primary esophageal cancer referred for resection to the Oakland Medical Center of the Kaiser-Permanente Northern California health plan who underwent this approach between January 2013 and August 2018 were included. Operative and clinical outcome variables were extracted from the electronic medical record, operating-room files, and manual chart review.

Results: 142 patients underwent the new procedure and care program; 121 (85.2\%) were men with mean age of 64.5 years. 127 (89.4\%) were adenocarcinoma; 117 (82.4\%) were clinical stage III or IVA. 115 (81.0\%) required no jejunostomy. Median hospital length-of-stay was 3 days and $8(5.6 \%)$ patients required admission to the intensive care unit. Postoperative complications occurred in $22(15.5 \%)$ patients within 30 days of the procedure. There were no inpatient deaths; one patient $(0.7 \%)$ died within 30 days following discharge and three additional deaths $(2.1 \%)$ occurred through 90 days of follow-up.

Conclusions: This approach resulted in excellent clinical outcomes, including short hospital stays with limited need for the intensive care unit, few perioperative complications, and relatively few patients requiring feeding tubes on discharge. This comprehensive approach to esophagectomy is feasible and provides another clinically meaningful advance in the progress of minimally invasive esophagectomy. Further development and dissemination of this method is warranted.

\section{Introduction}

Esophageal cancer is the seventh most common cancer worldwide and the sixth leading cause of cancer-related death (1), reflecting its generally poor prognosis. In 2018 in the United States, there were over 17,000 incident cases and 15,000 deaths (2). Overall five-year survival is approximately $20 \%$ (3), and most patients will die within one year of diagnosis (4).

This situation creates a compelling need to minimize treatment-associated morbidity to provide esophageal cancer patients with the maximum quality of life for their often-limited expected survival. However, the primary treatment modality for esophageal cancer, surgical resection, has been associated with high morbidity and mortality. In a review of Medicare data between 1997-2003, esophagectomies (primarily open procedures) were associated with an inpatient mortality of $3.0 \%$ and a 30 -day mortality of $14 \%$ (5).

In an effort to improve on the outcomes of esophagectomy, Cuschieri, et al. developed and were the first to report on a minimally invasive esophagectomy (MIE) approach in 1992 (6). The technique was considered experimental until Luketich et al.'s landmark 2003 series of 222 MIE procedures, which were associated with an operative mortality of only $1.4 \%$ (7). Since that time, the procedure has been widely adopted and has progressively evolved as thoracic surgeons continue to incorporate additional innovations into the technique.

Despite the advantages over conventional open resections, there remain important areas for continued improvement in the process and postoperative outcomes associated with MIE procedures. Recent data show that median hospital length of stay (LOS) remains at approximately one week for MIE (8-39). Median intensive care unit (ICU) length of stay, when reported, is typically between 1-3 days for both open and MIE procedures $(9,12,14,16,17,20,26,27,30-32,36,37,39,40)$. Reported 30-day readmission rates are typically $9 \%-15 \%$ $(11,18,22,32,41,42)$. Although minimally invasive surgical approaches to esophagectomy have important advantages, reported complication rates remain in the range of $23 \%$ - $65 \%(8,10,12,13,15-17,19,21-29,29,32,33,35,36,38-40,42-46)$. Furthermore, transabdominal jejunostomy feeding tubes are generally placed for post-operative nutrition, potentially causing postoperative complications (47) and delaying return-to-baseline functional status; routine feeding tube placement is described in most protocols and in three large series, $\geq 84 \%$ of patients were discharged home with feeding tubes $(20,37,40)$. Hence, there continue to be opportunities for further development and enhancement of the MIE approach. In addition, substantial advances have been made in perioperative care, such as enhanced-recovery-after-surgery (ERAS) protocols, providing potential additional improvements in patients' overall surgical experience.

Building on the notable progress made by prior surgical innovators, we sought to improve preoperative, intraoperative, and postoperative aspects of MIE, with the goal of improving esophageal cancer patients' morbidity, mortality, and return-to-baseline functional status. We report here our experience with a streamlined fully minimally invasive operative approach along with a comprehensive perioperative care program.

\section{Methods}


Study Design: We conducted a retrospective review of consecutive cases of Kaiser Permanente Northern California (KPNC) patients who underwent this streamlined MIE procedure and perioperative-care program (described below) and detailed in the accompanying document (Additional File 1). KPNC is an integrated health plan serving 4.4 million members through a network of 21 medical centers in Northern California. The demographics of KPNC approximate the underlying demographics of the geographic region (48). All study procedures were approved by the KPNC Institutional Review Board.

Subjects: Eligible patients were KPNC members referred for esophagectomy who underwent this MIE procedure at the KPNC Oakland Medical Center by one of five board-certified attending thoracic surgeons between January 2013 and August 2018; additional eligibility criteria included a surgical indication of primary esophageal cancer, a requirement that the procedure was elective, that the surgery consisted of the MIE only (i.e., not combined with another procedure during the same surgery), and that the patient had 90 days of postoperative follow-up at the time of data analysis (patients who died within 90 days of surgery were not excluded). All patients meeting these eligibility criteria were included and full ascertainment of all relevant patients was achieved by a search of the electronic medical record (EMR), operating-room records, and a list maintained by the first author. All patients who underwent the procedure in the specified interval were included in the final cohort, including those with extremely advanced disease for whom surgery was performed at the patient's request and were not expected to survive. Postoperative follow-up for surgical outcomes (including complications and mortality) was carried out for 90 days postoperatively on all patients; mortality follow-up was carried out to a maximum of 84.0 months (median: 29.0 months; survival curves were truncated when fewer than 10 patients remained at risk); data on mortality were obtained from the EMR and state and federal mortality databases.

Description of perioperative and operative procedures: Perioperative care was guided by strict adherence to ERAS protocols, which included patient education with preoperative nutritionist consultation, mandatory perioperative medicine clinic consultation, carbohydrate loading with clear liquids 2-to-4 hours preoperatively, avoidance of perioperative use of sedating medications, and use of nonopioid multimodal analgesia. Postoperatively, the urinary catheter and nasogastric tube were removed on the first day and a clear-liquid diet started and early ambulation instituted. Detailed descriptions of all aspects of the KPNC ERAS protocols are provided elsewhere $(49,50)$. Most patients are discharged on postoperative day 3 (patients are eligible for discharge on day 3 if they have no leak on the esophagram, absence of tachycardia or fever, are able to sustain hydration and nutrition with over 2 liters of fluid orally per day, their pain is adequately treated with oral medication, and they appear clinically well). Patients call or text the surgeon daily for 10 days after discharge after which they are seen in clinic; physician assistants assist in monitoring discharged patients.

The procedure described in this paper is classified as "IVL-LV" in the taxonomy of a recent consensus statement (51). Briefly, the MIE in this study was performed in the following manner: The abdominal portion was conducted through a $15 \mathrm{~mm}, 10 \mathrm{~mm}$, three mm ports and a 5 Nathanson liver retractor. The camera was operated by a surgical trainee. Both surgeon and assist employed two instruments. The hiatus was mobilized and Penrose drain placed, the greater curvature mobilized, the left gastric divided with a stapler and the stomach partially tubularized with three thick tissue stapler loads. Jejunostomy tube placement, the pyloroplasty, and the Kocherization of the duodenum were not done. To avoid trauma to the gastric conduit it was never grasped by instruments. The thoracic portion was conducted through four $10 \mathrm{~mm}$ ports and a $40-50 \mathrm{~mm}$ utility port. The pleura was incised caudal to cephalad and mobilized off the spine. The Penrose was retrieved at the hiatus and the esophagus and periesophageal tissue mobilized. A longitudinal incision was made in the upper esophagus to allow insertion of the anvil, the esophagus transected, and the anvil secured with two endoloop sutures. A gastrostomy was made on the lessor curvature and the stapler inserted. An anastomosis was created as proximal as possible and the tubularization complete leaving a 2 $\mathrm{cm}$ bridge. The pleura was closed with interrupted 2.0 silk sutures cranial to caudal.

Variables: Patient-related data included demographics and clinical comorbidities (i.e., specific comorbidities and the Charlson-Quan Comorbidity Index summary score (52)), American Society of Anesthesiologists (ASA) preoperative risk score (range 1-5) (53), Eastern Cooperative Oncology Group (ECOG) performance-status score (range 0-5) (54), and neoadjuvant therapy received. Tumor-related variables included cell type, primary esophageal site, clinical and pathologic stage (consistent with the American Joint Committee on Cancer (AJCC)/Union for International Cancer Control (UICC) staging system, $8^{\text {th }}$ edition, 2017 (55)) and regional lymph-node status. Variables related to the surgical procedure included both full operating-room time and "skin-to-skin" time (time between first incision and final closure), estimated blood loss, jejunostomy status, pleural-closure status and whether an intra-pyloric botulinum injection was used. Outcome variables included LOS for the overall hospitalization and for the ICU specifically as well as 30-day incidence of hospital readmission, emergency-department visits, whether the patient was discharged with a feeding tube in place, reoperation, and all-cause and cancer-specific mortality. Perioperative complications and post-discharge complications were all reviewed by the first author (SA) and categorized by the U.S. National Cancer Institute Common Terminology Criteria for Adverse Events (CTCAE) system, v5.0 (56). 
Data sources: Data for this study were obtained by extraction of relevant variables from the EMR database supplemented by manual chart review for those variables not available in discrete electronic form. Some cancer-related variables were obtained from a KPNC Cancer Registry maintained by the KPNC Division of Research for research purposes and for reporting to the Surveillance, Epidemiology, and End Results (SEER) program of the U.S. National Cancer Institute (57). Data domains extracted from the EMR included demographics, clinical comorbidities, overall hospital ICU length of stay, readmission rates, and mortality. Variables requiring manual chart review included clinical and pathologic staging, lymph-node involvement, specific procedure-related variables, operative times from anesthesia records, and procedure-related complications. Manual chart data extraction was conducted by SA, AA, and BH.

Data Analysis: Continuous variables were summarized as means with Wald $95 \%$ confidence intervals and/or medians with the associated interquartile ranges (IQRs). Categorical variables were summarized with percentages and $95 \%$ confidence intervals $(95 \% \mathrm{Cl})$ were calculated with the exact Clopper-Pearson method (58). Survival data for both total and cancer-specific mortality were summarized with Kaplan-Meier failure-time plots (59).

\section{Results}

Patients: One hundred fifty-two KPNC patients underwent this MIE procedure-and-care program between January 2013 and August 2018; of these, 10 patients were excluded for the following reasons: seven cases were complex procedures in which the MIE was combined with a second procedure during the same surgery (e.g., adrenalectomy, colon transposition, or lung lobectomy), two were unplanned salvage procedures, and one case was performed for recurrent esophageal cancer. The final analytic cohort was comprised of the remaining 142 patients (Table 1). No patient had a planned elective esophagectomy at this medical facility by any other procedure (e.g., open esophagectomy). All patients underwent the procedure for esophageal cancer, nearly all of whom had disease in the lower third of the esophagus or at the gastroesophageal junction $(90.8 \%)$ and had adenocarcinoma histology (89.4\%). Eighty-five cancers (59.9\%) were clinical stage III and 32 (22.5\%) were clinical stage IVA. The mean age of all patients was 64.5 years and the majority (85.2\%) were men. One hundred twenty-five (88.0\%) received some form of neoadjuvant therapy.

Operative outcomes: Of the 142 procedures, 1 required conversion to an open laparotomy due to intraoperative technical difficulties. The median total patient operating room time was 290 minutes (IQR: 255 to 348 minutes; mean: 306.5 minutes) and the median "skin-to-skin" time was 237 minutes (IQR: 210 to 290 minutes; mean: 254.6 minutes) (Table 2). One hundred fifteen patients (81.0\%, 95\% Cl: 73.6\% to $87.0 \%$ ) did not have a jejunostomy placed during or after surgery.

Clinical outcomes: The median hospital LOS was 3 days (IQR: 2 to 4 days); the mean was 3.6 days (95\% Cl: 3.1 to 4.0 days). Only 8 patients (5.6\%, 95\% Cl: $2.5 \%$ to $10.8 \%$ ) required postoperative care in the ICU (all were unplanned) and, of these, only 1 patient required care for more than 4 days (Table 3).

Twenty-two patients ( $15.5 \%, 95 \% \mathrm{Cl}: 10.0 \%$ to $22.5 \%$ ) suffered a total of 25 complications within 30 days following the surgical procedure (Table 3); 14 patients (9.9\%) experienced a complication with a CTCAE severity score of $>3$. The most common complications were pneumonia, atrial fibrillation, and anastomotic leaks (the frequencies of all complications are detailed in Table 3 ). In addition to these complications, 21 patients (14.8\%) had a postoperative anastomotic stricture (i.e., that required dilation any time during the full extended follow-up period).

Within the 30 days after discharge, 14 patients $(9.9 \%, 95 \% \mathrm{Cl}: 5.5 \%$ to $16.0 \%)$ were readmitted to the hospital. Thirty-six patients $(25.4 \%$, $95 \% \mathrm{Cl}: 18.4 \%$ to $33.3 \%)$ were evaluated in the emergency department, and 6 patients ( $4.2 \%, 95 \% \mathrm{Cl}: 1.6 \%$ to $9.0 \%)$ were taken back to the operating room (three for anastomotic leak, one for gastric conduit loss, one for empyema, and one for tracheostomy and jejunostomy to treat respiratory failure). No patient died intraoperatively or prior to discharge $(0 \%, 95 \% \mathrm{Cl}: 0 \%$ to $2.6 \%) ; 1$ patient $(0.7 \%, 95 \% \mathrm{Cl}: 0.02 \%$ to $3.9 \%$ ) died within 30 days post-procedure; 3 additional patients died between 31 and 90 days postoperatively (full 90-day mortality: 2.8\%, $95 \% \mathrm{Cl}: 0.8 \%$ to $7.1 \%$ ). The Kaplan-Meier product-limit estimate of the longer-term total mortality experience of this cohort is shown in Figure 1 (total median survival was 4.6 years); cancer-specific survival is shown in Figure 2.

\section{Discussion}

Esophageal cancer is a deadly disease, with an overall five-year survival of only $19 \%$ (4) and esophagectomy remains the mainstay of treatment. Since the introduction of the minimally invasive approach to esophagectomy in 1992 (6), there have been important improvements in the technique and outcomes associated with the procedure, though many patients continue to be burdened by surgical morbidity, lifestyle restrictions (e.g., use of feeding tubes), and prolonged hospitalization. Accordingly, thoracic surgeons have continued to build on prior innovations to further improve on the promise of MIE (60). 
In this paper, we describe the process and clinical outcomes associated with a streamlined surgical approach to MIE developed at our institution among 142 consecutive patients with esophageal cancer treated with this procedure (Figure 3 ). This surgical technique was built around a fully minimally invasive approach incorporating updated techniques used by our group and others, motivated by prior advances in the procedure. In addition, we were careful to adhere to the principles of ERAS (49) with careful patient preparation and close postdischarge outpatient follow-up, further optimizing both the surgical and perioperative experience. No patient was lost to follow-up for the assessment of 90-day postoperative outcomes.

In conjunction with well-coordinated preoperative and postoperative care, we found this approach was associated with excellent outcomes, substantially improving objective measures of surgical and perioperative performance as well as the patient experience. In particular, we found that this comprehensive perioperative and surgical approach was associated with relatively shorter operative times, decreased need for both intensive-care and overall inpatient hospitalization, reduced need for feeding tubes, and acceptable adverse-event, reoperation, and readmission rates.

For example, we observed a median inpatient LOS of 3 days in our series with no patient requiring a routine ICU admission and only $5.6 \%$ requiring a subsequent transfer to the ICU for management of complications. These results compare favorably with prior published MIE studies with reported hospital LOS's between 7 and 33 days (8-40); most studies reported LOS's of at least 12 days, with the largest case series reporting LOS's of 8 to 15 days $(18,20,22,32,35)$. The great majority of studies that provided data on intensive care unit LOS's reported a median of at least one day $(9,12,14,16,17,20,26,27,30-32,36,37,39,40,61)$. Furthermore, the elimination of a routine ICU admission and shorter overall LOS did not adversely affect rates of readmission or reoperation: our readmission rate was $12 \%$, similar to previously reported rates of $9-18 \%(11,18,22,32,41,42)$. In addition, only $19 \%(95 \% \mathrm{Cl}: 12.9 \%$ to $26.4 \%)$ of our patients required placement of a jejunostomy tube, compared with reported rates of $84 \%$ (37), 95\% (20), and $97 \%$ (40), among many other series that described routine jejunostomy-tube placement as part of the surgical protocol.

Comparing surgical complications across series is admittedly difficult since there is great variability in reporting standards. However, with respect to individual complications, we observed anastomotic leaks in 3 patients (2.1\%, 95\% Cl: $0.4 \%-6.0 \%)$ compared with others' reported rates that ranged from $0 \%$ to $21 \%(8,10-12,14,16,17,19,21,23-40,42-44,61-63)$ with a median rate of $10 \%$ and a range from $5.5 \%$ to $21 \%$ among the five largest series that reported relevant rates $(32,35,36,42,63)$. In our series, pulmonary complications occurred in 14 patients (9.9\%; $95 \%$ Cl: $5.5 \%$ to $16.0 \%$ ), including 9 cases (6.3\%) of pneumonia and 2 cases (1.4\%) of empyema; there were no cases of adult respiratory distress syndrome (ARDS) or chylothorax. These results compare favorably with rates from other centers with reported postoperative pneumonia rates ranging from $2 \%$ to $20 \%(10,13-16,19,22,25,28,29,35-38,40,43,44)$ with the median reported rate of $8 \%$, and reported rates of empyema ranging from $0 \%$ to $4.1 \%(15,20,35,37,39,42)$ with a median rate of $3.8 \%$. Rates of ARDS reported in prior series range from $1 \%$ to $8 \%(8,10,16,20,23,35,40,43)$ with a median of $3.3 \%$; reported rates of chylothorax range from $1 \%$ to $11 \%$ $(12,14,15,17,19,23,24,26,31,32,35,37-40,42,44,62)$ with the median reported rate of $3 \%$. No patient died during the index hospitalization and 30-day mortality was $0.7 \%$ (95\% Cl: $0.02 \%$ to $3.9 \%)$ compared with reported rates in other series of $0 \%-11 \%(9,11,12,16,18-20,22-$ $24,32,34-37,40,43,45,61,63$ ) (with most in the range of $2 \%-4 \%$ ).

The reasons for the favorable outcomes we observed were likely multifactorial. While the fundamental surgical principles remained unchanged for the esophagectomy itself, we streamlined several technical aspects, eliminating the need for the pyloroplasty, jejunostomy and Kocherization. Meticulous attention was made to avoid tissue trauma to the gastric conduit by utilizing a "no-grab" technique, implementing partial conduit tubularization, and avoiding a linear gastrotomy. Having two subspecialty thoracic surgeons working together further reduced time under anesthesia.

The decrease in hospital LOS reflects not only improved intraoperative techniques, but also intensive perioperative management. Saving the right pleura and reconstituting the mediastinal envelope eliminated the need for a feeding tube and allowed early removal of the nasogastric tube with resultant initiation of oral nutrition on the first postoperative day. Of particular note, only $19 \%$ of our patients required placement of a feeding jejunostomy tube compared to much higher rates reported in the literature. Employing a closed suction drain provided continued chest drainage, which could be continued as an outpatient to monitor for leaks. Postoperative pain management was simplified by administering long-acting intercostal nerve blocks thereby eliminating epidural catheters. Early alimentation and ambulation allowed the patient to recover earlier at home. There was daily telephone communication with a staff surgeon and on-demand access as necessary to monitor patients' progress and address any patient concerns. Return visits were mostly limited to drain removal. The combination of a streamlined procedure, strict adherence to ERAS protocols by a highly coordinated perioperative team, and close postoperative follow-up all likely contributed to the favorable patient outcome and experience.

Our case series has several strengths, including a consecutive closed cohort, complete 90-day follow-up, and detailed clinical and utilization EMR data. Our patient sample was typical of patients in other cohorts and trials in terms of age, gender, ASA classification, cancer stage, 
comorbidities, and use of neoadjuvant therapy. However, several limitations of this report should be noted. First, this study was based on a single-center, retrospective design. Additionally, this was a study of a streamlined surgical approach along with instituting a centralized multidisciplinary care method; therefore, it was not possible to determine the impact of each individual component on the improved outcomes. Although several surgeons performed the new procedure, suggesting the results are not limited to the practice of a single practitioner, generalizability will need to be validated in other practice settings. Finally, the retrospective data collection did not allow for assessment of standardized quality-of-life assessments.

\section{Conclusions}

We found that an enhanced method of performing esophagectomy, employing a full minimally invasive approach, combined with a welldeveloped multidisciplinary perioperative-care program resulted in important improvements and excellent outcomes for the initial surgical treatment of esophageal cancer among the patients in our series. Further research should examine the generalizability of this approach and continue its development (ideally employing comparative clinical trials) to further improve the clinical experience and outlook for patients with esophageal cancer eligible for surgical resection.

\section{Abbreviations}

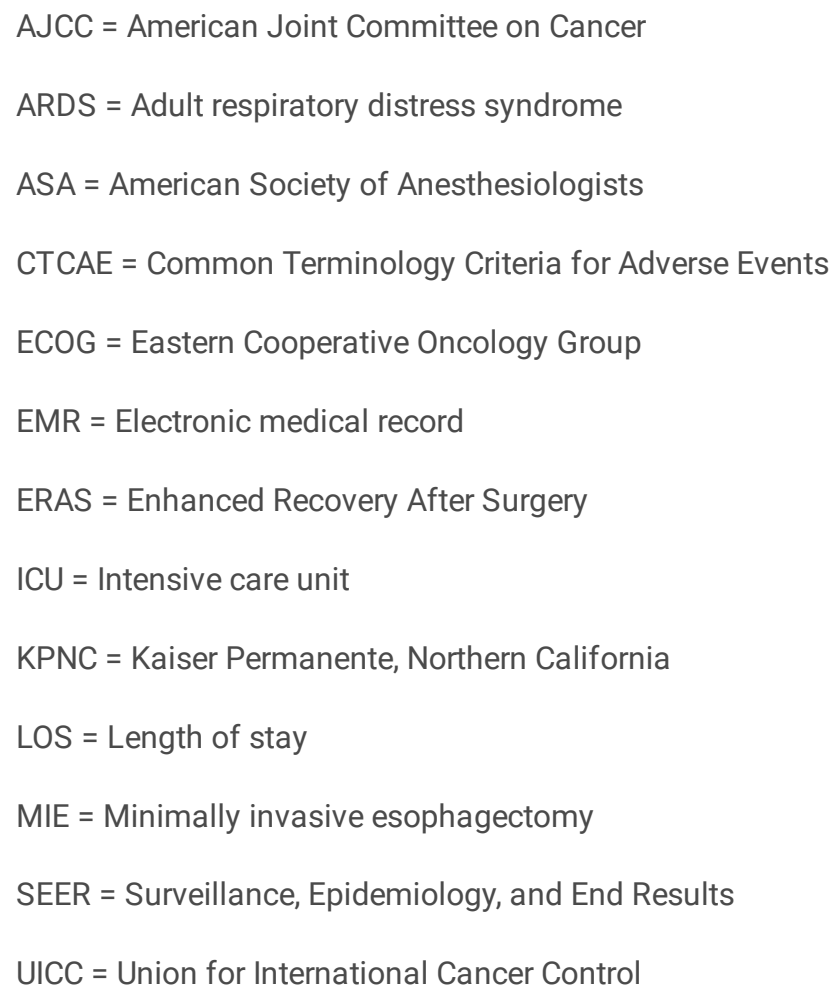

\section{Declarations}

Ethics approval and consent to participate: This study was conducted under full-committee approval from the KPNC Institutional Review Board (Approval Number: 1279152 (April 30, 2017)). As a data-only, secondary analysis of existing data, the requirement for individual consent by study subjects was waived by the IRB.

Consent for publication: We have a included a video of the surgical procedure ("Additional file 2"; .mp4 file). This video was created only after we obtained a full consent and waiver from the patient (which we have in our possession).

Availability of data and materials: The datasets used and analysed during the current study are available from the corresponding author on reasonable request.

Competing interests: The authors declare that they have no competing interests

Funding: This project was supported by The Permanente Medical Group's Delivery Science and Applied Research program 
Authors' contributions:

SKA: Conceived the study, conducted manual chart review for variables not available in discrete form in the electronic medical record, participated in writing the first draft of the manuscript, participated in the manuscript review and revisions

ARP: Participated in reviewing the data and in the manuscript review and revisions

$\mathrm{BHH}$ : Extracted the study data from the electronic medical record, conducted manual chart review for additional variables, participated in conducting the statistical analysis, participated in the manuscript review and revisions

JV: Participated in reviewing the data and in the manuscript review and revisions

SE: Participated in reviewing the data and in the manuscript review and revisions

ALA: Conducted manual chart review for variables not available in discrete form in the electronic medical record, participated in conducting the statistical analysis, participated in writing the first draft of the manuscript, participated in the manuscript review and revisions

Acknowledgements: Not applicable

\section{References}

1. Bray F, Ferlay J, Soerjomataram I, Siegel RL, Torre LA, Jemal A. Global cancer statistics 2018: GLOBOCAN estimates of incidence and mortality worldwide for 36 cancers in 185 countries. CA Cancer J Clin. 2018;68(6):394-424.

2. Siegel RL, Miller KD, Jemal A. Cancer statistics, 2018. CA Cancer J Clin. 2018;68(1):7-30.

3. Esophageal Cancer - Cancer Stat Facts [Internet]. SEER. [cited 2019 Apr 11]. Available from: https://seer.cancer.gov/statfacts/html/esoph.html

4. Njei B, McCarty TR, Birk JW. Trends in esophageal cancer survival in United States adults from 1973 to 2009 : A SEER database analysis. J Gastroenterol Hepatol. 2016 Jun;31(6):1141-6.

5. Ra J, Paulson EC, Kucharczuk J, Armstrong K, Wirtalla C, Rapaport-Kelz R, et al. Postoperative mortality after esophagectomy for cancer: development of a preoperative risk prediction model. Ann Surg Oncol. 2008 Jun;15(6):1577-84.

6. Cuschieri A, Shimi S, Banting S. Endoscopic oesophagectomy through a right thoracoscopic approach. J R Coll Surg Edinb. 1992 Feb;37(1):7-11.

7. Luketich JD, Alvelo-Rivera M, Buenaventura PO, Christie NA, McCaughan JS, Litle VR, et al. Minimally invasive esophagectomy: outcomes in 222 patients. Ann Surg. 2003 Oct;238(4):486-94; discussion 494-495.

8. Berger AC, Bloomenthal A, Weksler B, Evans N, Chojnacki KA, Yeo CJ, et al. Oncologic efficacy is not compromised, and may be improved with minimally invasive esophagectomy. J Am Coll Surg. 2011 Apr;212(4):560-6; discussion 566-568.

9. Biere SSAY, van Berge Henegouwen MI, Maas KW, Bonavina L, Rosman C, Garcia JR, et al. Minimally invasive versus open oesophagectomy for patients with oesophageal cancer: a multicentre, open-label, randomised controlled trial. Lancet Lond Engl. 2012 May 19;379(9829):1887-92.

10. Briez N, Piessen G, Torres F, Lebuffe G, Triboulet J-P, Mariette C. Effects of hybrid minimally invasive oesophagectomy on major postoperative pulmonary complications. Br J Surg. 2012 Nov;99(11):1547-53.

11. Findlay L, Yao C, Bennett DH, Byrom R, Davies N. Non-inferiority of minimally invasive oesophagectomy: an 8-year retrospective case series. Surg Endosc. 2017;31(9):3681-9.

12. Gao Y, Wang Y, Chen L, Zhao Y. Comparison of open three-field and minimally-invasive esophagectomy for esophageal cancer. Interact Cardiovasc Thorac Surg. 2011 Mar;12(3):366-9.

13. Glatz T, Marjanovic G, Kulemann B, Sick O, Hopt UT, Hoeppner J. Hybrid minimally invasive esophagectomy vs. open esophagectomy: a matched case analysis in 120 patients. Langenbecks Arch Surg. 2017 Mar;402(2):323-31.

14. Javidfar J, Bacchetta M, Yang JA, Miller J, D'Ovidio F, Ginsburg ME, et al. The use of a tailored surgical technique for minimally invasive esophagectomy. J Thorac Cardiovasc Surg. 2012 May;143(5):1125-9.

15. Kauppi J, Räsänen J, Sihvo E, Huuhtanen R, Nelskylä K, Salo J. Open versus minimally invasive esophagectomy: clinical outcomes for locally advanced esophageal adenocarcinoma. Surg Endosc. 2015 Sep;29(9):2614-9.

16. Kinjo Y, Kurita N, Nakamura F, Okabe H, Tanaka E, Kataoka Y, et al. Effectiveness of combined thoracoscopic-laparoscopic esophagectomy: comparison of postoperative complications and midterm oncological outcomes in patients with esophageal cancer.

Page $7 / 16$ 
Surg Endosc. 2012 Feb;26(2):381-90.

17. Kubo N, Ohira M, Yamashita Y, Sakurai K, Toyokawa T, Tanaka H, et al. The impact of combined thoracoscopic and laparoscopic surgery on pulmonary complications after radical esophagectomy in patients with resectable esophageal cancer. Anticancer Res. 2014 May;34(5):2399-404.

18. Lazzarino Al, Nagpal K, Bottle A, Faiz O, Moorthy K, Aylin P. Open versus minimally invasive esophagectomy: trends of utilization and associated outcomes in England. Ann Surg. 2010 Aug;252(2):292-8.

19. Li J, Shen Y, Tan L, Feng M, Wang H, Xi Y, et al. Is minimally invasive esophagectomy beneficial to elderly patients with esophageal cancer? Surg Endosc. 2015 Apr;29(4):925-30.

20. Luketich JD, Pennathur A, Awais O, Levy RM, Keeley S, Shende M, et al. Outcomes after minimally invasive esophagectomy: review of over 1000 patients. Ann Surg. 2012 Jul;256(1):95-103.

21. Maas KW, Biere SSAY, Scheepers JJG, Gisbertz SS, van-der-Peet DL, Cuesta MA. Laparoscopic versus open transhiatal esophagectomy for distal and junction cancer. Rev Espanola Enfermedades Dig Organo Of Soc Espanola Patol Dig. 2012 Apr;104(4):197-202.

22. Mamidanna R, Bottle A, Aylin P, Faiz O, Hanna GB. Short-term outcomes following open versus minimally invasive esophagectomy for cancer in England: a population-based national study. Ann Surg. 2012 Feb;255(2):197-203.

23. Mariette C, Markar SR, Dabakuyo-Yonli TS, Meunier B, Pezet D, Collet D, et al. Hybrid Minimally Invasive Esophagectomy for Esophageal Cancer. N Engl J Med. 2019 10;380(2):152-62.

24. Meng F, Li Y, Ma H, Yan M, Zhang R. Comparison of outcomes of open and minimally invasive esophagectomy in 183 patients with cancer. J Thorac Dis. 2014 Sep;6(9):1218-24.

25. Naffouje SA, Salloum RH, Khalaf Z, Salti GI. Outcomes of Open Versus Minimally Invasive Ivor-Lewis Esophagectomy for Cancer: A Propensity-Score Matched Analysis of NSQIP Database. Ann Surg Oncol. 2019 Jul;26(7):2001-10.

26. Noble F, Kelly JJ, Bailey IS, Byrne JP, Underwood TJ, South Coast Cancer Collaboration - Oesophago-Gastric (SC3-OG). A prospective comparison of totally minimally invasive versus open Ivor Lewis esophagectomy. Dis Esophagus Off J Int Soc Dis Esophagus. 2013 Apr;26(3):263-71.

27. Paireder M, Asari R, Kristo I, Rieder E, Zacherl J, Kabon B, et al. Morbidity in open versus minimally invasive hybrid esophagectomy (MIOMIE): Long-term results of a randomized controlled clinical study. Eur Surg ACA Acta Chir Austriaca. 2018;50(6):249-55.

28. Palazzo F, Rosato EL, Chaudhary A, Evans NR, Sendecki JA, Keith S, et al. Minimally invasive esophagectomy provides significant survival advantage compared with open or hybrid esophagectomy for patients with cancers of the esophagus and gastroesophageal junction. J Am Coll Surg. 2015 Apr;220(4):672-9.

29. Parameswaran R, Veeramootoo D, Krishnadas R, Cooper M, Berrisford R, Wajed S. Comparative experience of open and minimally invasive esophagogastric resection. World J Surg. 2009 Sep;33(9):1868-75.

30. Rodham P, Batty JA, McElnay PJ, Immanuel A. Does minimally invasive oesophagectomy provide a benefit in hospital length of stay when compared with open oesophagectomy? Interact Cardiovasc Thorac Surg. 2016 Mar;22(3):360-7.

31. Safranek PM, Cubitt J, Booth MI, Dehn TCB. Review of open and minimal access approaches to oesophagectomy for cancer. Br J Surg. 2010 Dec;97(12):1845-53.

32. Seesing MFJ, Gisbertz SS, Goense L, van Hillegersberg R, Kroon HM, Lagarde SM, et al. A Propensity Score Matched Analysis of Open Versus Minimally Invasive Transthoracic Esophagectomy in the Netherlands. Ann Surg. 2017;266(5):839-46.

33. Shen Y, Zhang Y, Tan L, Feng M, Wang H, Khan MA, et al. Extensive mediastinal lymphadenectomy during minimally invasive esophagectomy: optimal results from a single center. J Gastrointest Surg Off J Soc Surg Aliment Tract. 2012 Apr;16(4):715-21.

34. Shiraishi T, Kawahara K, Shirakusa T, Yamamoto S, Maekawa T. Risk analysis in resection of thoracic esophageal cancer in the era of endoscopic surgery. Ann Thorac Surg. 2006 Mar;81(3):1083-9.

35. Sihag S, Kosinski AS, Gaissert HA, Wright CD, Schipper PH. Minimally Invasive Versus Open Esophagectomy for Esophageal Cancer: A Comparison of Early Surgical Outcomes From The Society of Thoracic Surgeons National Database. Ann Thorac Surg. 2016 Apr;101(4):1281-8; discussion 1288-1289.

36. Smithers BM, Gotley DC, Martin I, Thomas JM. Comparison of the outcomes between open and minimally invasive esophagectomy. Ann Surg. 2007 Feb;245(2):232-40.

37. Tapias LF, Mathisen DJ, Wright CD, Wain JC, Gaissert HA, Muniappan A, et al. Outcomes With Open and Minimally Invasive Ivor Lewis Esophagectomy After Neoadjuvant Therapy. Ann Thorac Surg. 2016 Mar;101(3):1097-103.

38. Yamasaki M, Miyata H, Fujiwara Y, Takiguchi S, Nakajima K, Kurokawa Y, et al. Minimally invasive esophagectomy for esophageal cancer: comparative analysis of open and hand-assisted laparoscopic abdominal lymphadenectomy with gastric conduit

Page 8/16 
reconstruction. J Surg Oncol. 2011 Nov 1;104(6):623-8.

39. Zingg U, McQuinn A, DiValentino D, Esterman AJ, Bessell JR, Thompson SK, et al. Minimally invasive versus open esophagectomy for patients with esophageal cancer. Ann Thorac Surg. 2009 Mar;87(3):911-9.

40. Luketich JD, Pennathur A, Franchetti Y, Catalano PJ, Swanson S, Sugarbaker DJ, et al. Minimally invasive esophagectomy: results of a prospective phase II multicenter trial-the eastern cooperative oncology group (E2202) study. Ann Surg. 2015 Apr;261(4):702-7.

41. Conroy MA, Dolan JP, Latour E, Lim JY, Siegal S, Schipper PH, et al. Readmission Patterns at 30 and 90 Days after Esophagectomy: A Single NCl-Designated Cancer Center Experience. J Am Coll Surg. 2017 Oct 1;225(4):e94.

42. Sakamoto T, Fujiogi M, Matsui H, Fushimi K, Yasunaga H. Comparing Perioperative Mortality and Morbidity of Minimally Invasive Esophagectomy Versus Open Esophagectomy for Esophageal Cancer: A Nationwide Retrospective Analysis. Ann Surg. 2019 Jul 25;

43. Nafteux P, Moons J, Coosemans W, Decaluwé H, Decker G, De Leyn P, et al. Minimally invasive oesophagectomy: a valuable alternative to open oesophagectomy for the treatment of early oesophageal and gastro-oesophageal junction carcinoma. Eur $\mathrm{J}$ Cardio-Thorac Surg Off J Eur Assoc Cardio-Thorac Surg. 2011 Dec;40(6):1455-63; discussion 1463-1464.

44. Osugi H, Takemura M, Higashino M, Takada N, Lee S, Kinoshita H. A comparison of video-assisted thoracoscopic oesophagectomy and radical lymph node dissection for squamous cell cancer of the oesophagus with open operation. Br J Surg. 2003 Jan;90(1):10813.

45. Takeno S, Takahashi Y, Moroga T, Kawahara K, Yamashita Y, Ohtaki M. Retrospective study using the propensity score to clarify the oncologic feasibility of thoracoscopic esophagectomy in patients with esophageal cancer. World J Surg. 2013 Jul;37(7):1673-80.

46. Yibulayin W, Abulizi S, Lv H, Sun W. Minimally invasive oesophagectomy versus open esophagectomy for resectable esophageal cancer: a meta-analysis. World J Surg Oncol. 2016 Dec 8;14(1):304.

47. Kidane B, Kaaki S, Hirpara DH, Shen YC, Bassili A, Allison F, et al. Emergency department use is high after esophagectomy and feeding tube problems are the biggest culprit. J Thorac Cardiovasc Surg. 2018;156(6):2340-8.

48. Gordon NP. Similarity of adult Kaiser Permanente Members to the adult population in Kaiser Permanente's Northern California service area: Comparisons based on the $2017 / 2018$ cycle of the California Health Interview Survey [Internet]. Kaiser Permanente Northern California Division of Research; 2020 [cited 2020 Jan 15]. Available from:

https://divisionofresearch.kaiserpermanente.org/projects/memberhealthsurvey/SiteCollectionDocuments/compare_kp_ncal_chis201718.pdf

49. Liu VX, Rosas E, Hwang J, Cain E, Foss-Durant A, Clopp M, et al. Enhanced Recovery After Surgery Program Implementation in 2 Surgical Populations in an Integrated Health Care Delivery System. JAMA Surg. 2017 19;152(7):e171032.

50. Liu VX, Rosas E, Hwang JC, Cain E, Foss-Durant A, Clopp M, et al. The Kaiser Permanente Northern California Enhanced Recovery After Surgery Program: Design, Development, and Implementation. Perm J. 2017;21:17-003.

51. Cerfolio RJ, Laliberte A-S, Blackmon S, Ruurda JP, Hillegersberg R van, Sarkaria I, et al. Minimally Invasive Esophagectomy: A Consensus Statement. Ann Thorac Surg. 2020 Oct;110(4):1417-26.

52. Quan H, Li B, Couris CM, Fushimi K, Graham P, Hider P, et al. Updating and validating the Charlson comorbidity index and score for risk adjustment in hospital discharge abstracts using data from 6 countries. Am J Epidemiol. 2011 Mar 15;173(6):676-82.

53. Dripps RD. New classification of physical status. Anesthesiology. 1963;24:11.

54. Oken MM, Creech RH, Tormey DC, Horton J, Davis TE, McFadden ET, et al. Toxicity and response criteria of the Eastern Cooperative Oncology Group. Am J Clin Oncol. 1982 Dec;5(6):649-55.

55. Saltzman, J.R., Gibson, M.K. Clinical manifestations, diagnosis, and staging of esophageal cancer. In: UpToDate [Internet]. Waltham, MA: UpToDate; 2020 [cited 2020 Nov 24]. Available from: https://www.uptodate.com/contents/clinical-manifestations-diagnosis-andstaging-of-esophageal-cancer?

search=esophageal\%20cancer\&source=search_result\&selectedTitle=1 150\&usage_type=default\&display_rank=1\#H3217766884

56. Common Terminology Criteria for Adverse Events (CTCAE) | Protocol Development | CTEP [Internet]. [cited 2020 Jan 4]. Available from: https://ctep.cancer.gov/protocolDevelopment/electronic_applications/ctc.htm

57. Surveillance, Epidemiology, and End Results Program [Internet]. SEER. [cited 2018 Dec 21]. Available from: https://seer.cancer.gov/index.html

58. Clopper C, Pearson E. The use of confidence or fiducial limits illustrated in the case of the binomial. Biometrika. 1934;26(4):404-13.

59. Kleinbaum DG, Klein M. Survival analysis. Vol. 2nd. New York: Springer; 2005.

60. Zhang J, Wang R, Liu S, Luketich JD, Chen S, Chen H, et al. Refinement of minimally invasive esophagectomy techniques after 15 years of experience. J Gastrointest Surg Off J Soc Surg Aliment Tract. 2012 Sep;16(9):1768-74.

Page 9/16 
61. Lee J-M, Cheng J-W, Lin M-T, Huang P-M, Chen J-S, Lee Y-C. Is there any benefit to incorporating a laparoscopic procedure into minimally invasive esophagectomy? The impact on perioperative results in patients with esophageal cancer. World J Surg. 2011 Apr;35(4):790-7.

62. Hamouda AH, Forshaw MJ, Tsigritis K, Jones GE, Noorani AS, Rohatgi A, et al. Perioperative outcomes after transition from conventional to minimally invasive Ivor-Lewis esophagectomy in a specialized center. Surg Endosc. 2010 Apr;24(4):865-9.

63. Schröder W, Hölscher AH, Bludau M, Vallböhmer D, Bollschweiler E, Gutschow C. Ivor-Lewis esophagectomy with and without laparoscopic conditioning of the gastric conduit. World J Surg. 2010 Apr;34(4):738-43.

\section{Tables}


Table 1

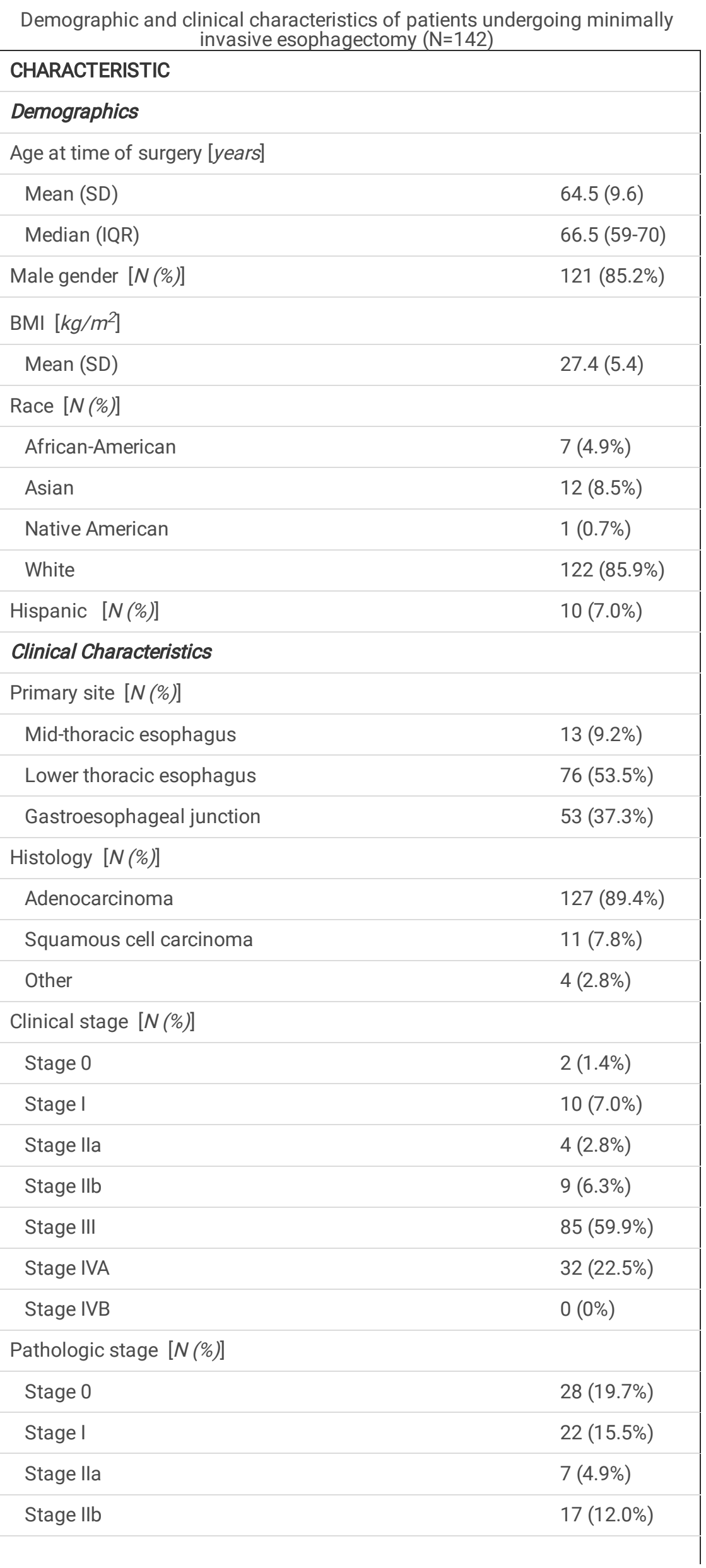

Page $11 / 16$ 


\begin{tabular}{|c|c|}
\hline Stage III & $39(27.5 \%)$ \\
\hline Stage IVA & $28(19.7 \%)$ \\
\hline Stage IVB & $1(0.7 \%)$ \\
\hline Regional lymph nodes involved (Clinical staging) [N(\%)] & $87(61.3 \%)$ \\
\hline Regional lymph nodes involved (Pathologic staging) [N(\%)] & $53(37.3 \%)$ \\
\hline \multicolumn{2}{|l|}{ ECOG Performance Status $[N(\%)]$} \\
\hline 0 & $42(29.6 \%)$ \\
\hline 1 & $48(33.8 \%)$ \\
\hline 2 & $12(8.5 \%)$ \\
\hline Unknown & $40(28.2 \%)$ \\
\hline \multicolumn{2}{|l|}{ Neoadjuvant therapy $[N(\%)]$} \\
\hline Radiation therapy only & $1(0.7 \%)$ \\
\hline Chemotherapy only & $15(10.6 \%)$ \\
\hline Chemoradiation & $109(76.8 \%)$ \\
\hline None & $17(12.0 \%)$ \\
\hline \multicolumn{2}{|l|}{ Preoperative ASA Category $[N(\%)]$} \\
\hline 1 & $0(0 \%)$ \\
\hline 2 & $50(35.2 \%)$ \\
\hline 3 & $91(64.1 \%)$ \\
\hline 4 & $1(0.7 \%)$ \\
\hline 5 & $0(0 \%)$ \\
\hline \multicolumn{2}{|l|}{ Clinical Comorbidities [N (\%)] } \\
\hline Hypertension & $87(61.3 \%)$ \\
\hline Diabetes & $47(33.1 \%)$ \\
\hline Coronary artery disease & $43(30.3 \%)$ \\
\hline Heart failure & $8(5.6 \%)$ \\
\hline Chronic renal insufficiency & $26(18.3 \%)$ \\
\hline Chronic obstructive pulmonary disease & $13(9.2 \%)$ \\
\hline Stroke/Transient ischemic attack & $4(2.8 \%)$ \\
\hline \multicolumn{2}{|l|}{ Charlson-Quan Comorbidity Index } \\
\hline Mean (SD) & $6.0(5.6-6.4)$ \\
\hline Median (IQR) & $7(4-8)$ \\
\hline
\end{tabular}

Acronyms:

ASA: American Society of Anesthesiologists

BMI: Body Mass Index

ECOG: Eastern Cooperative Oncology Group

IQR: Interquartile range

Page 12/16 
SD: Standard deviation

Table 2

Operative parameter characteristics ( $\mathrm{N}=142)$

\begin{tabular}{|ll|}
\hline CHARACTERISTIC & \\
\hline Intraoperative time (minutes) & \\
\hline Full operating room time & $306.5(73.7)$ \\
\hline Mean (SD) & $290(255-348)$ \\
\hline Median (IQR) & \\
\hline "Skin-to-skin" time & $254.6(65.5)$ \\
\hline Mean (SD) & $237(210-290)$ \\
\hline Median (IQR) & $142.0(143.9)$ \\
\hline Estimated blood loss (cc) & $100(50-200)$ \\
\hline Mean (SD) & \\
\hline Median (IQR) & $128(90.1 \%)$ \\
\hline Resection Margin & $14(9.9 \%)^{\star}$ \\
\hline R0 & $11(7.8 \%)$ \\
\hline R1 & $3(2.1 \%)$ \\
\hline Circumferential & $15(11-21)$ \\
\hline Longitudinal & $37.3 \%$ \\
\hline Lymph nodes excised (median (IQR)) & $3(2.1 \%)$ \\
\hline Positive lymph node pathology (\%) & $6(4.2 \%)$ \\
\hline Jejunostomy [N (\%)] & $115(81.0 \%)$ \\
\hline Preoperative & $37(26.1 \%)$ \\
\hline Intraoperative & $99(69.7 \%)$ \\
\hline Postoperative & \\
\hline None & \\
\hline Pylorus injection of botulinum toxin [N(\%) & \\
\hline Pleura closed [N (\%)] & \\
\hline
\end{tabular}

*Note: two of these patients were alive and well at least four years after surgery, suggesting these patients likely had a complete resection with negative margins

Abbreviations:

IQR: Interquartile range

R0: clean surgical margins; no evidence of residual tumor

R1: evidence of residual tumor at surgical margin

SD: Standard deviation 
Table 3

Patient clinical outcomes $(\mathrm{N}=142)$

\begin{tabular}{|c|c|}
\hline CLINICAL OUTCOMES & $N(\%)$ \\
\hline \multicolumn{2}{|l|}{ Hospital length of stay [days] } \\
\hline Mean (SD) & $3.6(3.0)$ \\
\hline Median (IQR) & $3(2-4)$ \\
\hline \multicolumn{2}{|l|}{ Intensive care length of stay [N (\%)] } \\
\hline No intensive care days & $134(94.4 \%)$ \\
\hline 1 - 2 days & $4(2.8 \%)$ \\
\hline 3 - 4 days & $3(2.1 \%)$ \\
\hline$\geq 5$ days & $1(0.7 \%)$ \\
\hline Readmission within 30 days [N (\%)] & $17(12.0 \%)$ \\
\hline Post-discharge emergency department visit within 30 days [N (\%)] & $36(25.4 \%)$ \\
\hline Return to operating room within 30 days [N (\%)] & $9(6.3 \%)$ \\
\hline Required post-operative balloon pyloroplasty [N (\%)] & $33(23.2 \%)$ \\
\hline \multicolumn{2}{|l|}{ Mortality [N (\%)] } \\
\hline In-hospital & $0(0 \%)$ \\
\hline Within 30 days of discharge & $1(0.7 \%)$ \\
\hline 31-90 days after discharge & $3(2.1 \%)$ \\
\hline Patients with $\geq 1$ complication within 30 days of surgery [N (\%)] & $22(15.5 \%)$ \\
\hline \multicolumn{2}{|l|}{ Highest CTCAE complication grade } \\
\hline Grade 1 & $0(0 \%)$ \\
\hline Grade 2 & $8(5.6 \%)$ \\
\hline Grade 3 & $8(5.6 \%)$ \\
\hline Grade 4 & $4(2.8 \%)$ \\
\hline Grade 5 (death) & $2(1.4 \%)$ \\
\hline \multicolumn{2}{|l|}{ Specific Complications } \\
\hline Atrial fibrillation & $4(2.8 \%)$ \\
\hline Anastomotic leak & $3(2.1 \%)$ \\
\hline Dehydration & $1(0.7 \%)$ \\
\hline Empyema & $2(1.4 \%)$ \\
\hline Gastric conduit necrosis & $1(0.7 \%)$ \\
\hline Myocardial infarction & $1(0.7 \%)$ \\
\hline Pleural effusion & $1(0.7 \%)$ \\
\hline Pneumonia & $9(6.3 \%)$ \\
\hline Pneumothorax & $1(0.7 \%)$ \\
\hline Respiratory failure & $1(0.7 \%)$ \\
\hline Urinary tract infection (cystitis) & $1(0.7 \%)$ \\
\hline
\end{tabular}

Acronyms: 
IQR: Interquartile range

SD: Standard deviation

\section{Figure}

Figure 3 not available with this version.

\section{Figures}

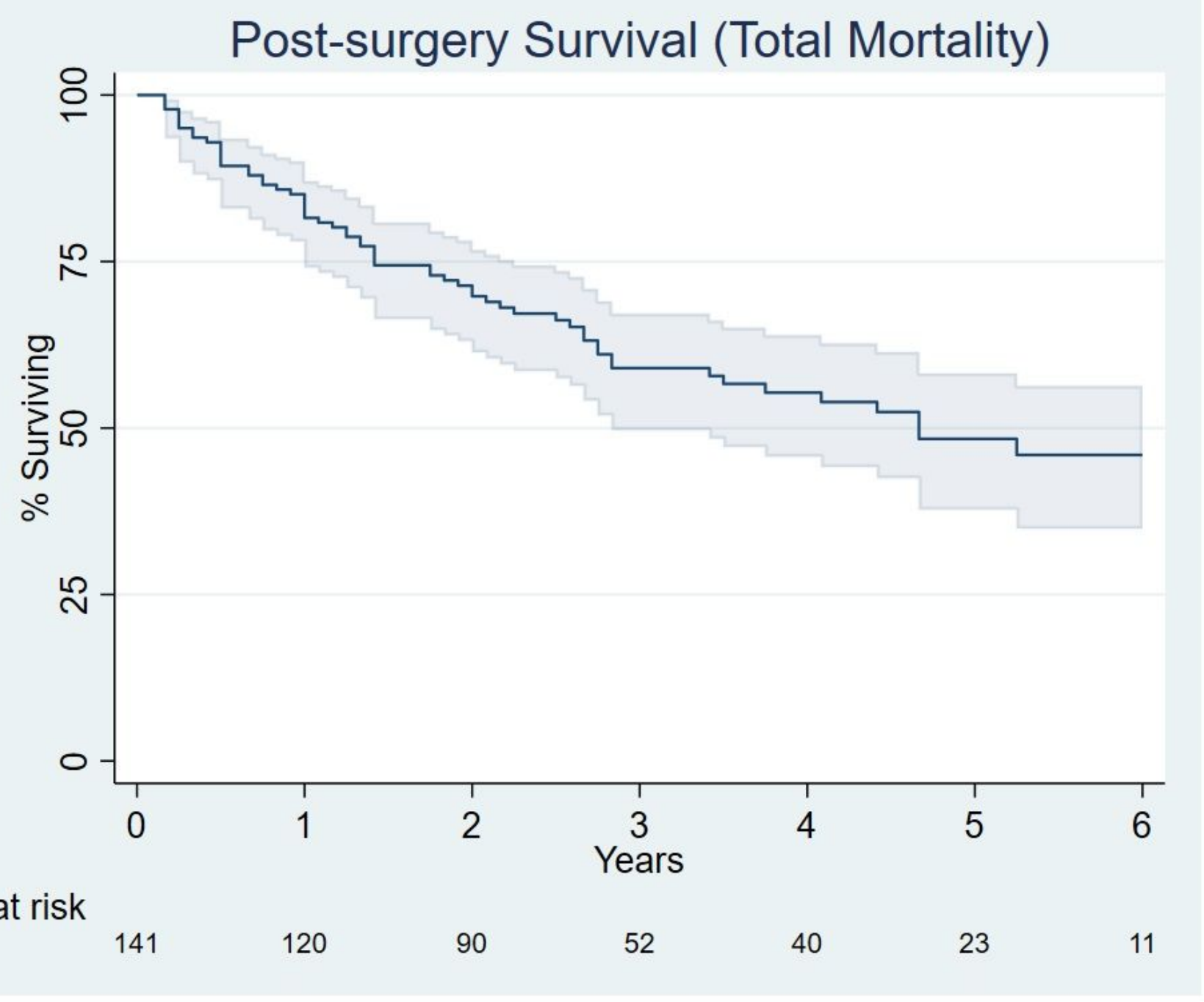

Figure 1

Kaplan-Meier overall survival curve for 142 patients undergoing minimally invasive esophagectomy described in this manuscript (point estimates (dark blue lines) with 95\% confidence intervals (grey intervals)); data truncated at 6 years when fewer than 10 patients had follow-up data after this point. 


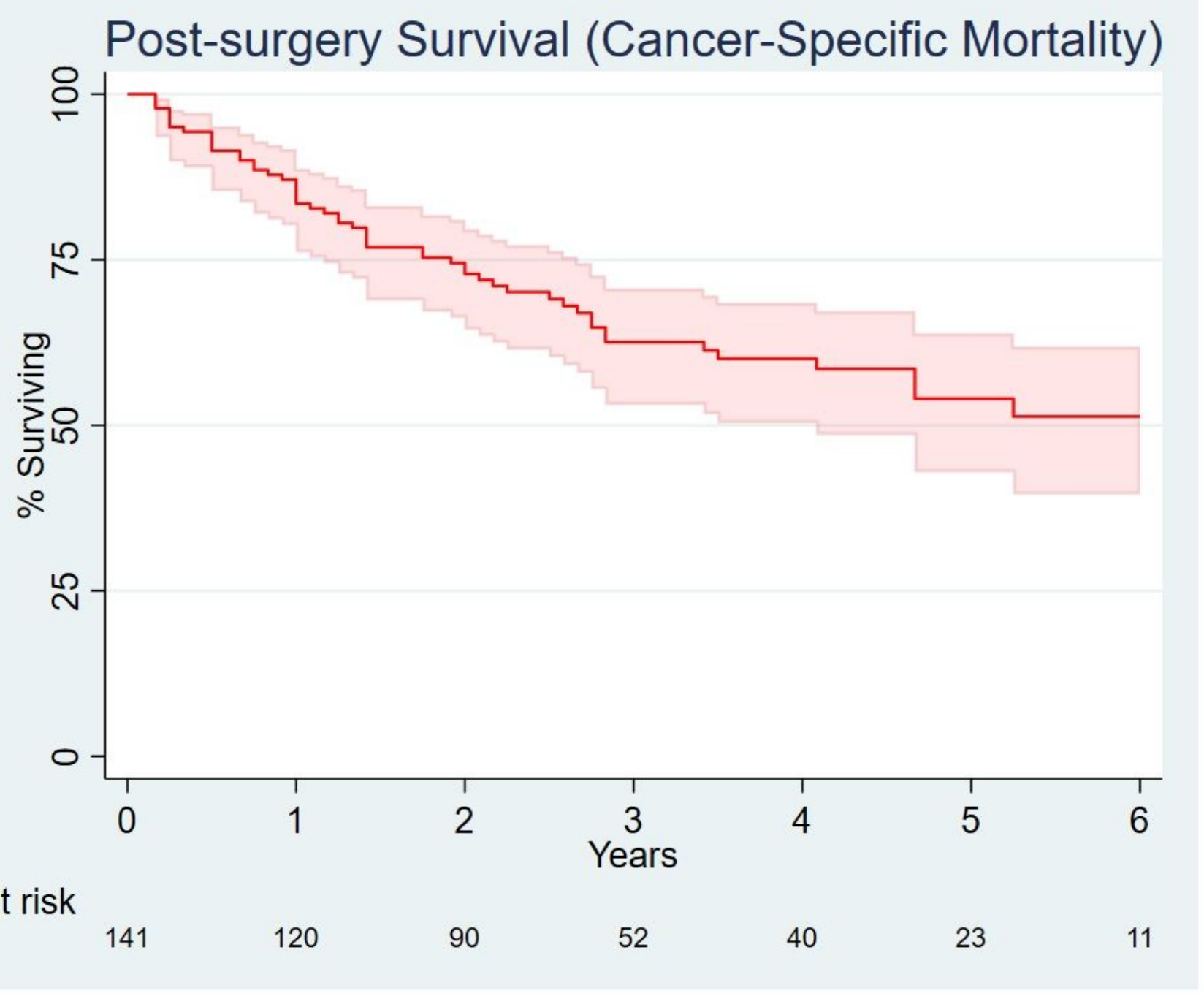

Figure 2

Kaplan-Meier curve for esophageal cancer-specific survival of 142 patients undergoing minimally invasive esophagectomy described in this manuscript (point estimates (dark blue lines) with 95\% confidence intervals (grey intervals)); data truncated at 6 years when fewer than 10 patients had follow-up data after this point.

\section{Supplementary Files}

This is a list of supplementary files associated with this preprint. Click to download.

- AshikuAdditionalFile1.docx 